\title{
An advanced method for flood risk analysis in river deltas, applied to societal flood fatality risk in the Netherlands
}

\author{
K. M. de Bruijn ${ }^{1}$, F. L. M. Diermanse ${ }^{2}$, and J. V. L. Beckers ${ }^{2}$ \\ ${ }^{1}$ Scenarios and Policy Analysis, Deltares, Delft, the Netherlands \\ ${ }^{2}$ Inland Water Systems, Deltares, Delft, the Netherlands \\ Correspondence to: K. M. de Bruijn (karin.debruijn@deltares.nl)
}

Received: 11 January 2014 - Published in Nat. Hazards Earth Syst. Sci. Discuss.: 19 February 2014

Revised: 12 September 2014 - Accepted: 15 September 2014 - Published: 14 October 2014

\begin{abstract}
This paper discusses a new method for flood risk assessment in river deltas. Flood risk analysis of river deltas is complex, because both storm surges and river discharges may cause flooding and the effect of upstream breaches on downstream water levels and flood risk must be taken into account. This paper presents a Monte Carlo-based flood risk analysis framework for policy making, which considers both storm surges and river flood waves and includes effects from hydrodynamic interaction on flood risk. It was applied to analyse societal flood fatality risk in the Rhine-Meuse delta.
\end{abstract}

\section{Introduction}

The National Water Plan (NWP) in the Netherlands requires a reconsideration of flood risk management standards based on cost benefit analyses and fatality (loss of life) risk assessments (Ministerie van Verkeer and Waterstaat, 2009). The NWP induced an extensive research programme into flood risk and in particular flood fatality risk in the Netherlands. Fatality risk also attracts increasing attention in flood risk management and research in other countries, such as France (Lalande, 2012), the USA (US Department of the Interior, 2011), the UK (Di Mauro and De Bruijn, 2012), Belgium (IMDC, 2005) and Indonesia (Marchand et al., 2009).

Flood fatality risk can be assessed both from an individual and societal point of view. The individual flood fatality risk relates to the probability of a person dying as a result of a flood event at a certain location. This perspective focuses on hazardous locations without taking into account the population density at those locations. Individual risks have been assessed for the Netherlands as part of the implementation of the NWP (De Bruijn et al., 2010; Beckers et al., 2012).

Societal flood fatality risk is related to the probability of events with many fatalities. It is expressed by an FN curve, which gives the annual probability of an event with $N$ or more fatalities (De Bruijn et al., 2010). It combines information on flood hazards, flood extents and population density in flood-prone areas. In the Netherlands, the Rhine-Meuse delta (both the tidal- and non-tidal part) contributes most to the societal flood fatality risk (Beckers and De Bruijn, 2011; Beckers et al., 2012).

This paper focuses on the development of a method to analyse societal flood fatality risks in river deltas with flood protection infrastructure, such as the Rhine-Meuse delta. The method needs to be able to calculate the societal flood fatality risk under current and future conditions, including effects of various flood risk management strategies.

To be applicable, the method should comply with three requirements. Firstly, it must be applicable to an area as large as the (Dutch part) of the Rhine-Meuse delta. Secondly, it should account for the most relevant processes which determine the number of flood fatalities per event. Since in the Netherlands floods are caused by defence breaches, the flood extent of an event is linked to the number and locations of defence breaches.

To obtain a realistic estimate of the number and location of breaches (and the corresponding consequences), the hydrodynamic interaction between locations needs to be taken into account. By hydrodynamic interaction we mean the decrease of water levels at potential breach locations due to a breach elsewhere in the river system. This decrease of water levels may have a significant effect on the failure probabilities of 
(downstream) flood defences and thus on flood risk in fluvial systems (Van Mierlo et al., 2007; Apel et al., 2009; Vorogushyn et al., 2010). Secondly, since upstream breaches may also influence the flood probabilities in the tidal river part, an integrated analysis of both the river-dominated and the tidal part of the delta must be carried out. Hydrodynamic interaction is generally not relevant in areas where a flooding will not cause a reduction of water levels in the water ways, such as in coastal systems. A third requirement is that the method should facilitate the analysis of societal flood risks corresponding with various potential flood risk management strategies.

The method should result in an accurate FN curve, potential numbers of fatalities for the whole system, insight into the contributions of different subareas and insight into the most relevant flood events (set of breach locations, river discharges and sea water levels). These results support the consideration of societal flood fatality risks in the decision on flood protection standards and flood risk management strategies.

This paper presents and discusses the method that was developed to meet these requirements and its application on societal flood fatality risks in the Rhine-Meuse delta. The method may also be used to analyse economic risks and the approach is also applicable to other river deltas.

\section{Existing flood risk assessment methods}

Various methods have been developed to analyse flood risks in deltas protected by flood defences and the impact of flood risk management strategies on those flood risks. Approaches usually include an analysis of possible loads or threats, analysis of the reliability of the protection infrastructure, analysis of breach sizes or breach growth given failure, modelling of the expected flood patterns and assessments of the associated consequences. Most methods are quantitative, but there are qualitative methods which focus on mapping the most important risk factors and combine them to a qualitative indication of risk. The "risky places" method which identifies areas where many fatalities may occur is an example of such methods (De Bruijn and Klijn, 2009). To explain the need for a new method for societal risk analysis of river deltas, we provide a brief overview of existing approaches.

To quantify flood risks, both deterministic and probabilistic methods may be used. In deterministic approaches risk is assessed by simulating a single "design" event instead of the whole range of possible events, and subsequent assessment of the corresponding flood patterns and impacts. When a certain probability is assigned to the design event, the approach is sometimes referred to as "semi-probabilistic", because it does take probabilities into account to some extent. Since the full range of possible outcomes is not explored in this approach, the actual risk may be a grossly under- or overestimated. The approach is generally applied in explorative analyses in which for example effects of climate change on flood risks are studied, when various long-term strategies are compared, or when the areas with highest flood risk must be identified. They may also be used in the analysis of measures. Then mostly an uncertainty or robustness factor is added to the outcome to take into account uncertainties. These deterministic approaches have the potential to deal with detailed information e.g. from 2-D flood inundation models, but may also be based on indicative maps of the most important flood hazard and flood vulnerability indicators. Examples of deterministic approaches are the quantification of numbers of fatalities given flood hazard information, such as the "deterministic framework for the assessment of injury and loss of life to floods" of Penning-Rowsell et al. (2005), the exploratory nation-wide fatality risk assessment in the Netherlands (Jonkman et al., 2008), the analysis for the second sustainability outlook of the Netherlands (Klijn et al., 2012), the long-term flood risk management strategy research for the Scheldt Estuary (De Bruijn et al., 2008) and tsunami risk modelling (Marchand et al., 2009).

\subsection{Probabilistic approaches}

Comprehensive flood risk analyses require the consideration of uncertainties in both hazards and vulnerability parameters, which is only possible in probabilistic approaches (Sayers et al., 2002; Apel et al., 2004; Gouldby et al., 2013; Vorogushyn et al., 2010; Van Mierlo et al., 2007). Probabilistic approaches are based on the awareness that most data and models are uncertain and that these uncertainties can be expressed in probability density functions. The outcome of a probabilistic approach may for example be a probability of failure, the probability of exceedance of a certain parameter, or a loss exceedance curve (a curve which gives the annual probability of events with more than $\mathrm{X}$ euro damage). Probabilistic approaches are being used in flood risk management, for example in the national risk assessments of the Netherlands (VNK2) (Jongejan et al., 2011; Den Heijer and Diermanse, 2012) and in the UK (Hall et al. 2005). For the analysis of societal risk in the Rhine-Meuse delta, we need a probabilistic approach to be able to account for the complex interactions and the combined threat of both storm surges and river discharges. We briefly describe some existing probabilistic approaches here and their shortcomings in relation to our needs.

In the Dutch National Risk assessment project (VNK2) economic and fatality risks of "dike rings" (areas surrounded by levees or higher grounds) in the Netherlands are being studied by first analysing defence section failure probabilities, as a result of various failure mechanisms, followed by an integration of the failure probabilities of many defence sections to the failure probability of the dike ring. This procedure requires knowledge or assumptions on the correlations between failures at different locations. The consequences associated with defence failure at each location are taken into 
account to derive a total flood risk per dike ring area. The VNK project does not consider the combined risk for the Rhine-Meuse delta or the Netherlands as a whole, but focuses on results per dike ring. The effect of breaches in other dike rings is not taken into account, which may cause a significant overestimation of the flood risk.

For the preliminary large-scale risk assessment of England and Wales also a probabilistic approach was developed (Hall et al., 2005). Gouldby et al. (2013) slightly adapted the approach and studied fatality risks. In these approaches, load reduction at downstream defence sections due to defence failures in the system was not taken into account. The approach of Hall et al. (2005) and Gouldby et al. (2013) is suitable for coastal defence structures and for small river valleys. However, for fluvial systems such as large rivers and estuaries where the effect of water retention on flood probabilities and flood risks may be significant, this retention effect should be taken into account.

\subsection{Why consider hydrodynamic interaction}

In large river systems, the probability of breaching in one of the downstream dike rings depends on what happens upstream in a way that cannot be approximated by an assumption of full dependency or independency. Especially for societal risk, which requires the total number of fatalities per event and thus the number of breaches per event, the consideration of hydrodynamic interaction is important. The effect of hydrodynamic interaction on flood probabilities and flood risk depends on the spatial variation of the hydraulic load and strength of the flood defences, the moment at which a defence breaks (beginning/peak or after the peak of a flood wave), and the available storage volume of the flood-prone areas in relation to the discharge volume in the river. The effect of a breach on downstream water levels and thus flood probabilities can be significant, as Olson and Morton (2012) and Apel et al. (2009) described. In the Mississippi River in 2011 the US Army made a breach and used the New Madrid Floodway to lower the water levels in the river with about $80 \mathrm{~cm}$ (Olson and Morton, 2012).

There are studies which include hydrodynamic interaction in flood hazard analysis. Apel et al. (2004) and Van Mierlo et al. (2007) provided methods to include the effect of hydrodynamic interaction in risk analysis and their work was improved in time (Apel et al., 2009; Vrouwenvelder et al., 2010). Apel et al. (2009) continued on the work of Apel et al. (2004) and studied the effect of upstream defence breaches on downstream flood frequencies for the Rhine River from Cologne to Rees. They used a probabilistic method to show that defence breaches have a significant effect on downstream discharges and on the probability of exceedance of design discharge levels. By considering hydrodynamic interaction, the $1: 5000$ year discharge at location Rees (at the Dutch-German border) reduces from
$17500 \mathrm{~m}^{3} \mathrm{~s}^{-1}$ to about $15500 \mathrm{~m}^{3} \mathrm{~s}^{-1}$. The effect of this reduction on flood risks was not studied.

Van Mierlo et al. (2007) developed an approach to incorporate hydrodynamic interaction in risk analysis and Vrouwenvelder et al. (2010) applied it on a dike ring in the Rhine-Meuse delta in the Netherlands. They calculated flood probabilities at predefined potential breach locations without consideration of hydrodynamic interaction, then they sampled river flood waves and assessed whether the sampled flood waves could result in one or more breaches. If so, the flood waves were simulated with the 2-D Sobek overland model (Dhondia and Stelling, 2004; Hesselink et al., 2003) to determine the flood pattern. The consequences of the flooding were determined with the Standard Dutch Damage and Fatality Model (HIS-SSM, Kok et al., 2005). Finally, the risk was assessed as the sum of the damage divided by the number of samples. Their approach was computationally very timeconsuming. One Monte Carlo simulation took about 2 to 6 days per run (2 GHz Linux PC in 2010). Such a long calculation time for one defence strength means that this method is not feasible for the analysis of a complete river system.

Vorogushyn et al. (2010) developed a method to include hydrodynamic interaction in hazard assessment and applied it on the Elbe River. They calculated hazard maps using a Monte Carlo analysis and coupled three models in a dynamic way: (1) a 1-D unsteady hydrodynamic model for river routing, (2) a probabilistic defence breach model to determine possible defence breach locations, breach growth and the outflow of discharges and (3) a 2-D (storage cell) based inundation model for the protected parts of the flood plains. The method resulted in probabilistic flood hazard maps for four "hazard scenarios" (for recurrence times of 100, 200, 500 and 1000 years) and for different flood hazard parameters. Vorogushyn et al. (2010) thus focused on flood hazards and did not consider flood impacts or risks. Vorogushyn et al. (2012) applied the method of Vorogushyn et al. (2010) to analyse the effects of a flood detention area and to do so, added damage assessment to the method. They study the uncertainties in damage per "hazard scenario" by taking into account the uncertainties in flood depths and by calculating damage with different damage assessment models. Finally, they integrated the four hazard scenario outcomes to one risk figure. They did not sample from the whole discharge probability density function.

The approach of Vorogushyn et al. $(2010,2012)$ is applicable to river areas. However, it is difficult to apply in river deltas where both storm surges and river discharges are relevant, since it is impossible to define one hazard scenario as the once-in-1000-year hazard scenario for the delta as a whole: in the upstream part the once-in-1000-year water level will be related to the once-in-1000-year discharge, near the coast it will be related to the one-in-1000-year sea water level, while in the transition area between the tidal and non-tidal area events such as the $1 / 10$ year water level in combination with a $1 / 10$ year river discharge might produce 
the $1 / 1000$ year water level. For delta areas thus a different approach is needed which considers the whole range of possible sea water levels and river discharges in an integrated way.

In Beckers and De Bruijn (2011), a probabilistic approach was used to assess the societal flood fatality risk in the Netherlands. They considered correlation between breaches and hydrodynamic interaction in the river area by using estimated correlation factors between dike rings and by expert assumptions on the retention effect of breaches on downstream breach probabilities. The hydrodynamic interaction of breach locations on downstream flood probabilities must thus be known beforehand. An event tree of all combinations of dike ring flood scenarios was constructed to evaluate the probability of a given number of fatalities. In order to keep the computational effort feasible, the dike rings were used as basic elements in the event tree, instead of the far more numerous defence sections. Furthermore, the tidal river area was considered independent from the non-tidal river area. The results of this study showed that the river area (tidal and non-tidal together) contributes most to the flood fatality risks in the Netherlands (De Bruijn et al., 2010; Beckers et al., 2012). Weak points in this study were the assumptions needed for the correlation between breaching of dike rings and the use of dike rings as basic units in the event tree, where individual defence sections would be more appropriate. The flood probabilities and flood consequences vary significantly between the different defence sections within one dike ring. This variation is lost when averages are used.

\subsection{What we need to add}

To assess societal risks of river deltas we cannot follow an approach which focuses on dike rings independently from what happens in other dike rings as was done by Jongejan et al. (2012), nor can we assume full correlation between different defence sections as done for the UK (Hall et al., 2005; Gouldby et al., 2013). Instead, we need to include the effects of hydrodynamic interaction on flood probabilities to get accurate estimates of the location and number of breaches and fatalities. The existing approaches to include hydrodynamic effects are either to complex and calculation time demanding to apply on a large scale (Vrouwenvelder et al., 2010), based on assumptions (Beckers et al., 2012) or they are developed for areas without tidal or storm surge influences (Vorogushyn et al., 2010). In river deltas where discharges and storm surges and combinations of both may cause flooding, it is not possible to directly link water levels with a certain probability, e.g the once-in-1000-year water level, to a hazard scenario, such as the once-in-1000-year discharge as Vorogushyn et al. (2010) could do for the Elbe River. There is no such thing as "the" once-in-1000-year event. The probability of water levels of downstream locations is dominated by storm surges, the water levels of upstream locations by river discharges and the water level probabilities within the transition part are influenced both by storm surges and river discharges. Therefore, an approach which jointly considers discharges and storm surges needs to be developed for such areas. Furthermore, most existing approaches focus on flood hazards, or economic risks. Our approach focuses on fatality risks and therefore also needs evacuation success as an uncertain input variable.

\section{The probabilistic risk assessment method as applied to the Rhine-Meuse delta}

\subsection{Overview}

This paper discusses a method which provides an FN curve to assess societal risk which is applicable to river deltas with a flood defence infrastructure. It takes into account the effect of breaches on downstream flood hazards, flood probabilities and risks, and it jointly considers all relevant threats (storm surges, river flows and the behaviour of storm surge barriers). It includes the analysis of fatalities due to breaches and takes into account evacuation of people. The analysis of societal risks on this spatial scale, for river deltas threatened both by storm surges and river discharges, taking into account hydrodynamic effects of breaches, has not been carried out before. The method allows the analysis of societal risk corresponding with different flood risk management strategies.

Our method is based on Monte Carlo simulation (MCS). To accelerate the simulation an advanced importance sampling technique is used for the sampling of load variables (sea water levels, river discharges at the upper boundary and the functioning of the storm surge barrier) and the flood plain modelling is simplified (see Sects. 3.3 and 3.4).

A schematic overview of the probabilistic risk assessment method is provided in Fig. 1. Besides pre- and postprocessing of input and output data, it consists of three main steps, which are explained in the following sections:

1. sampling of the load, strength and evacuation response variables;

2. the hydrodynamic modelling of the sampled events to see where breaches occur;

3. the translation of the model outcomes to flood fatalities per breach location and per sampled event.

The most important outputs are FN curves, Potential Loss of Life (expected annual number of fatalities) for the area as a whole and the contributions of the three subzones (tidal, nontidal and transition zone) to the total risk.

\subsection{Schematisation and data requirements for the Rhine-Meuse delta}

The case study of the Rhine-Meuse delta includes all main branches in the Rhine and Meuse delta between Lobith 


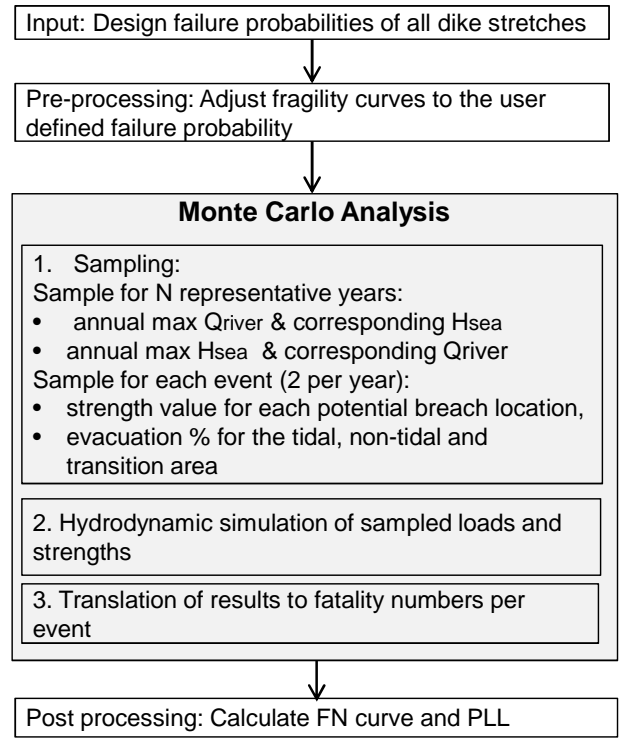

Data requirements:

- Statistics of Qriver, Hsea, evacuation

- Fragility curves of levees at all potential breach locations

- Model schematisation

- Flood fatalities given a breach for each potential breach location

Figure 1. Schematic overview of the probabilistic risk assessment method for river deltas.

(along the Rhine at the German-Dutch boundary), Lith (along the Meuse), Maasmond and the IJssel lake and the surrounding flood-prone areas (see Fig. 2).

To model potential dike breaches and their consequences, 171 potential breach locations have been defined (see Fig. 2). Each of these locations is representative of a defence stretch with a length varying from $400 \mathrm{~m}$ to about $34 \mathrm{~km}$. The potential breach locations were selected based on their expected consequences in the case of a failure. If somewhere a breach is expected to result in significantly different flood impacts than a neighbouring breach, an additional breach location was defined. In areas with secondary embankments, or where land use differs from place to place or areas with a significant slope, more breaches are selected than in flat homogeneous polder areas (Kok and Van der Doef, 2008). The length of the defence stretch for which the location is representative is taken into account in the probability (in general longer embankments have a larger failure probability if everything else is equal). For each defence stretch a fragility curve is derived which provides the probability of failure anywhere along the defence stretch as a function of the river water level. Details on these are provided in the following sections.

The probabilistic framework is used to assess the societal flood risk for different sets of potential flood protection standards. The flood protection standards are, therefore, defined as input per defence section. In these protection standards, the effect of hydrodynamic interaction is not taken into account: they provide the flood probability per dike section if only that section could fail. A defence section can contain one or more potential breach locations. The mean values of the fragility curves of the potential breach locations are shifted in an iterative procedure to ensure that the fail-

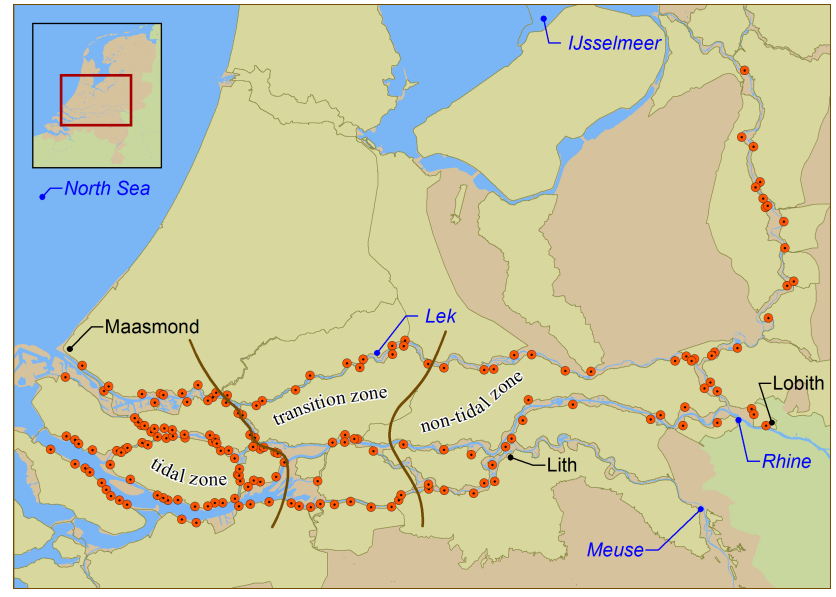

Figure 2. Map of the Rhine-Meuse delta with the boundaries of the studied area (Lobith, Lith, IJssellake, North Sea), the three zones dominated by different flood types (tidal zone, non-tidal zone and transition zone), and the potential breach locations (red dots).

ure probabilities of each defence section correspond with the user-defined protection standard (see Sect. 3.3.2).

\subsection{Sampling load, strength and evacuation response parameters}

The probabilistic method is based on MCS for load, strength and evacuation fraction. The MCS method was chosen because of the large number of breach locations for which defence strengths need to be sampled. Other probabilistic techniques, such as numerical integration or FORM, are less efficient for large numbers of random variables (De Bruijn and Diermanse, 2013; Diermanse et al., 2014). 


\subsubsection{Sampling load parameters}

Flooding in the Dutch Rhine and Meuse delta is caused by storm surges and by extreme river discharges coming from the upstream catchments of the Rhine and Meuse rivers. In the tidal river area, floods are not only linked to the storm surge severity, but also to the functioning of the storm surge barrier near the Maasmond, the Maeslant Barrier. The Rhine delta can be subdivided into three areas based on the event type which contributes most to the flood risk (see Fig. 2):

1. the river-dominated area, which may become flooded due to high discharges in the Rhine or Meuse river;

2. the tidal area, where the influence of storm surges is dominant: in this area, flooding may occur when a storm surge raises the local water levels and the storm surge barrier fails to close;

3. the transition zone: the area where flooding may occur due to a combination of a storm surge and a high river flood wave at the same time.

To obtain accurate flood risk estimates, flood events of all three types must be represented well. For each event, four variables are sampled in the MCS, which together determine the hydraulic load: the discharge of the Rhine River at Lobith, near the German border, the discharge of the Meuse River at the upstream location Lith, the sea water level at the Maasmond and the functioning of the Maeslant Barrier.

For each simulated year two types of events are sampled:

- a combination of an extreme river discharge and coinciding sea water level: the extreme river discharge is sampled from the annual maxima distribution and the sea water level from the distribution of tidal peak sea water levels.

- a combination of an extreme sea water level and coinciding river discharge: the extreme sea water level is sampled from the distribution of annual maximum sea levels and the river discharge from the daily river discharge statistics.

The general expression for the distribution function of annual maximum discharges of the Rhine and Meuse rivers is the Generalized Extreme Value distribution Type I (Gumbel). The coefficients $a$ and $b$ are fitted to a series of approximately 100 annual maxima that is corrected for anthropogenic and natural changes in the river bed over the years (De Bruijn and Diermanse, 2013):

$P(Q<q)=\exp \left(-\exp \left(-\frac{q-b}{a}\right)\right)$.

The fitted coefficients are $a=1316.45 \mathrm{~m}^{3} \mathrm{~s}^{-1}, \quad b=$ $6612.5 \mathrm{~m}^{3} \mathrm{~s}^{-1}$ for the Rhine River at Lobith and $a=$
$342.12 \mathrm{~m}^{3} \mathrm{~s}^{-1}$ and $b=1190.34 \mathrm{~m}^{3} \mathrm{~s}^{-1}$ for the Meuse River at Lith. The daily discharges were sampled directly from an observed time series of approximately 100 years. The river discharges of Rhine and Meuse are correlated. The correlation of 0.6 is taken into account by sampling combinations of Rhine and Meuse discharge from a Gaussian copula with correlation equal to 0.6 .

For the annual maximum water level, the conditional Weibull distribution is used to describe (non-) exceedance probabilities of annual maximum sea water levels at Maasmond:

$P(M \leq m \mid m>\omega)=1-\exp \left[(\omega / \sigma)^{\xi}-(h / \sigma)^{\xi}\right]$,

where $M$ is the annual maximum sea water level (in metres above datum, in this case NAP), $m$ is a potential realization of $M$ and $\omega, \sigma$ and $\xi$ are the location, scale and shape parameter respectively. Exceedance frequencies of high sea water levels can be derived by multiplying the probabilities that follow from Eq. (2) with the frequency of exceedance, $\lambda$, of threshold $\omega$. The value of $\lambda$ is determined by counting the number of peaks above the threshold and dividing by the number of years of record. Their values are in this case: $\omega=1.97 \mathrm{~m}+\mathrm{NAP}, \lambda=7.237$ year- $1, \xi=$ $0.57 \mathrm{~m}+\mathrm{NAP}, \sigma=0.0157 \mathrm{~m}+\mathrm{NAP}$.

The daily sea water level conditions, which are used to sample the sea water level coinciding with an annual maximum discharge, are derived from histograms of observed tidal peak water levels (Diermanse et al., 2014). The high river discharge wave lasts for several weeks and even the peak of the wave may last several days. This duration must be taken into account in the probability distribution from which the peak sea water level is sampled. We used a simplified approach to take this duration effect into account. We assumed that the combination of high sea water level and high river discharge can occur during a period of $K$ tidal periods and, assuming the hydrograph is symmetric, starts at $K / 2$ tidal periods before the peak discharge and ends at $K / 2$ periods after the peak discharge. The default value of $K$ is chosen to be 12 , i.e. about 6.5 days. This value is also used in standard Dutch probability assessment tool PCRING (Steenbergen et al., 2004). The value of $K$ is applied in the sampling procedure of the (peak) sea water level. The probability distribution function, $F_{\mathrm{S}}(s)$, for the peak sea water level for a single tidal period is

$F_{\mathrm{S}}(s)=P[S<s]$.

In the Monte Carlo procedure, the maximum sea water level of a period of $K$ tidal periods will be sampled. This value has the following distribution function:

$F_{\mathrm{S}}^{*}(s)=P[S<s]^{K}=\left(F_{\mathrm{S}}(s)\right)^{K}$.

The assumed duration $K$ thus influences the distribution function from which the maximum sea water level is sampled. An increase in the value of $K$ increases the probability 
of higher peak sea water levels being sampled. This is exactly the duration effect that needed to be incorporated in the approach: the longer the duration of a high discharge event, the higher the probability that the sea water level exceeds a given high threshold. A detailed description on the sampling techniques is provided in Diermanse et al. (2014).

\section{Maeslant barrier}

The functioning of the Maeslant Barrier is also sampled for each scenario. There are two possibilities: if the barrier functions, it closes upon request - that is if the water level at Rotterdam exceeds $3 \mathrm{~m}+\mathrm{NAP}$; if a failing storm surge barrier is sampled, the barrier will not close. The probability that a non-functioning barrier is sampled is $1 \%$ per event.

\section{Importance sampling}

The efficiency of the MCS is enhanced by importance sampling. The approach followed to obtain an effective sampling strategy differs from the adaptive sampling schemes as used by for example Steenackers et al. (2009), Allaix and Carbone (2011) and Dawson and Hall (2006). In those schemes the sampling density function $h(x)$ is iteratively adapted by assigning larger sampling densities to events that contribute most to the flood risk in earlier iterations. However, for our decision-making process, not only the flood risk of the entire delta area is required, but also the flood risk of all the individual polder areas that are protected by flood defences. Based on knowledge of the system, a sampling strategy was selected which gives accurate results in all subareas (Diermanse et al., 2014) and a reasonable convergence of the risk estimate.

In this sampling strategy, the original probability distribution for the maximum sea water levels, $f(x)$, is replaced by a uniform distribution function $h(x)$. This leads to all water levels being equally sampled. The same is done for the distribution of annual and daily peak discharges. The distribution of daily sea water levels is replaced by a composite function in which both peak water levels and intermediate water levels are represented well. Finally, the sampling failure probability of the Maeslant Barrier was increased from 1 to $10 \%$, since especially the situations with a failing storm surge barrier contribute significantly to the flood risk in the western part of the tidal river area. Because the sampling does not use the actual distribution function, the estimator of the failure probability as applied in Crude Monte Carlo needs to be adapted:

$\hat{P}_{f}=\frac{\sum_{i=1}^{N} \mathrm{I}(Z(x)) \frac{f(x)}{h(x)}}{N}$,

where is the estimate of $P_{f}, I$ is the indicator function $(I=1$ if $Z<0$, and 0 otherwise. $Z$ is a limit state function which represents failure. Failure occurs when $Z<0) . f(x)$ is the

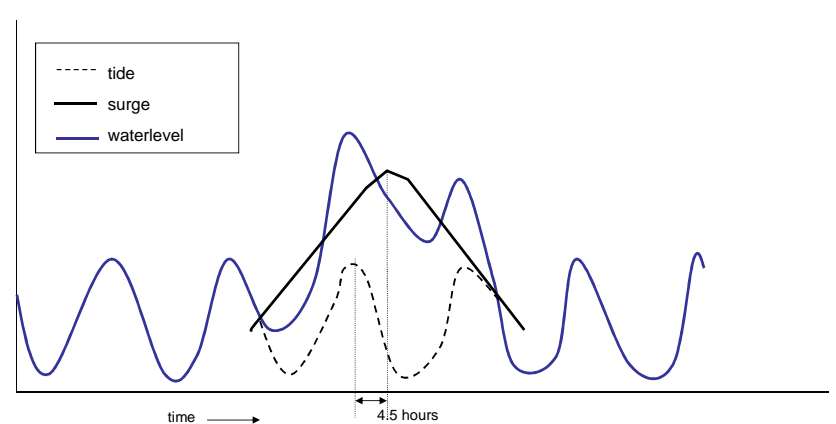

Figure 3. The sea water level is determined by tide and storm surge.

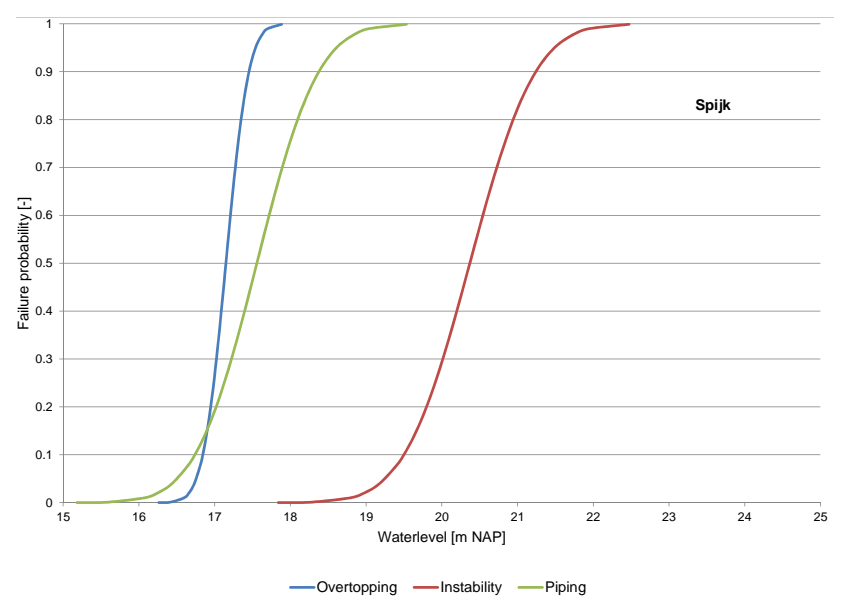

Figure 4. The fragility curves for the location Spijk upstream along the Rhine River.

probability density function, and $h(x)$ the sampling function. In the translation of the outcomes, the weights of the samples are thus corrected by the factor equal to $f(x) / h(x)$. Diermanse et al. (2014) discuss the sampling strategy in detail.

In the MCS, a total of 2000 events were sampled (two sampled events for 1000 representative years).

\section{Translation to time series}

In order to translate each sampled peak value into a timedependent discharge time series, a standard hydrograph shape was used (De Bruijn and Diermanse, 2013). The river flood wave shape used is equal to the standard flood wave applied to calculate the official Dutch design water levels for flood defences (Ministerie van Verkeer and Waterstaat, 2007). The peak of the Rhine discharge at Lobith is assumed to occur at the same time as the peak of the Meuse discharge at Lith. A standard sea water level hydrograph was derived from a combination of a standard tidal pattern and a storm surge hydrograph. The phase difference between the peak of the astronomic tide and the peak of the storm surge is fixed at $-4.5 \mathrm{~h}$, which is in accordance with the assumptions in the statutory safety assessment (HR2006, WTI2011). Figure 3 

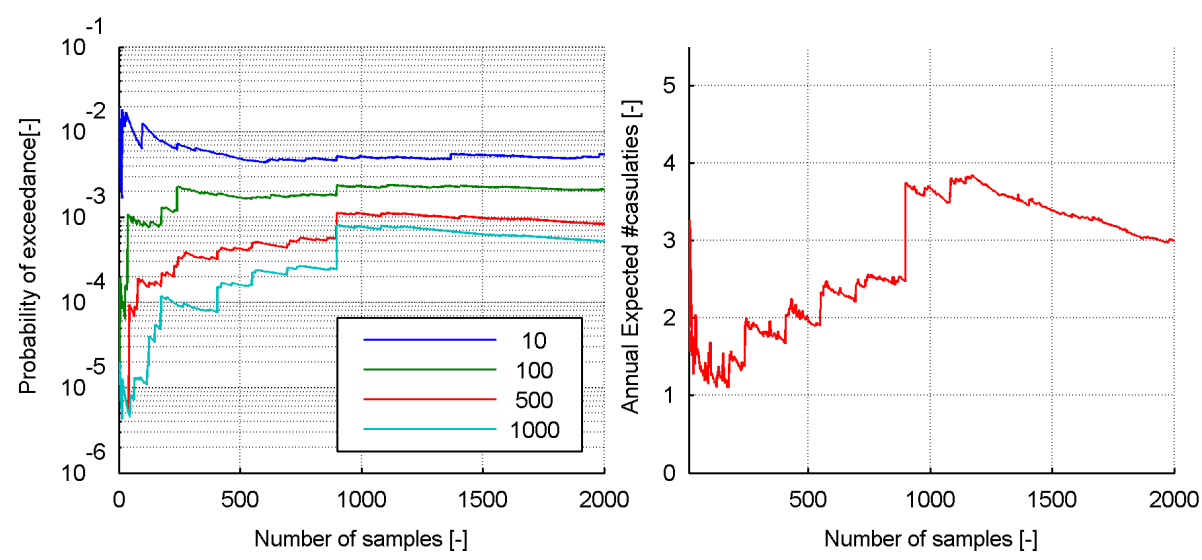

Figure 5. Convergence of the probability of exceedance of events with more than 10, 100, 5000 and 1000 fatalities (left) and the annual number of fatalities (right).

illustrates the hydrograph of the tide, storm surge and the combined sea water level. The peak of the sea water level occurs 2 days after the peak of the river discharge. This implies that the peaks arrive approximately at the same time in the transition area, i.e. the area that is influenced by both river discharges and sea level. For a detailed explanation we refer to De Bruijn and Diermanse (2013).

\subsubsection{Sampling strength parameters}

In the Rhine-Meuse delta area, 171 potential breach locations were identified (see Fig. 2 and Sect. 3.2). The strength of each defence stretch at each potential breach location is expressed by the lowest water level which causes the defence to fail. For each event, this critical water level is sampled for all potential breach locations from the fragility curves of those locations. Fragility curves describe the probability of a breach as a function of the water level $(H)$. Figure 4 shows as an example the fragility curves for location Spijk, near the upstream Rhine boundary. The shape of the fragility curve differs per failure mechanism. In this paper, overtopping, macro-instability and piping were considered. The fragility curve of piping is less steep than the one for overtopping, which means that failure can occur due to a wider range of water levels. For defence sections for which piping is dominant the uncertainty on the strength of the embankment, or the maximum water level which the embankment can still resist, is thus rather larger. This uncertainty is caused by the influence of other factors besides water level, such as the duration of the high water level and various geotechnical characteristics of the flood defence.

The fragility curves were constructed based on data of the subsoil and data of the flood defences such as the outer slope, the crest width and the presence of a ditch. The Dike Assessment Module (DAM module) was used to construct "typical Dutch defences" which correspond to the Dutch safety standards and design criteria on which Dutch defences are based (Van der Meij, 2013; De Bruijn et al., 2014). Next, DAM was used to calculate the probability of failure corresponding with a certain water level. This was repeated for a range of water levels to obtain the fragility curve (Van der Meij and Lopez de la Cruz, 2013). The fragility curves obtained in this procedure were discussed with experts (De Bruijn et al., 2014). The sensitivity of the FN curve and of the identified most relevant defence sections (sections which contribute most to the societal risks) for a range of realistic fragility curves was found to be low (De Bruijn et al., 2014).

The fragility curves are subsequently adapted in order to make sure that they comply with the user-provided flood protection standards. To adapt the fragility curves, first the local water level statistics at each breach location were derived based on 154 model simulations without breaches with different load combinations (7 sea water levels, 11 discharge peaks and 2 storm surge barrier states). Secondly, the mean value of the fragility curve is changed in iterative procedure based on the calculated water level statistics until the failure probability of the defence section matches the desired flood probability (with a fast routing model which does not consider hydrodynamic interaction). The shape of the fragility curve and thus its standard deviation is not changed.

Samples of fragility curves between different locations are assumed to be uncorrelated, because most of the potential breach locations are located far from each other.

\subsubsection{Sampling evacuation response parameters}

The expected number of fatalities as a result of a flood depends not only on the characteristics of the flooding scenario, but also on the population density and on the number of people that have been evacuated before the onset of the flooding. The fraction of the inhabitants who can be evacuated depends on the time available and the required time for evacuation, which differ between the three subareas (tidal, non-tidal and transition zone). In the probabilistic framework, the success 
rate of the evacuation, which varies between 0 and $90 \%$, is sampled from a probability distribution. Different distributions were derived for the three different regions: the nontidal river area, the tidal river area and the transition area, based on Maaskant et al. (2009b) and also used in Beckers and De Bruijn (2011). The evacuation fraction in the nontidal riverine area is on average $75 \%$, while in the tidal river area it is on average $15 \%$. In the river-dominated area, an accurate flood forecast can generally be made several days in advance and the road capacity is large in comparison to the population density. In the tidal area, the forecast lead times are typically less than a day, while the population density is very high. This explains the small values for the evacuation percentages in the tidal area compared to the non-tidal area. For the transition area, the evacuation success is considered correlated with the flood threat: if the flood is caused by a high river discharge, the forecast lead time is usually longer which increases the probability of a successful evacuation. Therefore, in the transition area the evacuation percentage is set equal to the sampled value for the river-dominated area in those events which have a Rhine peak discharge higher than $12000 \mathrm{~m}^{3} \mathrm{~s}^{-1}$ at Lobith. For other events, the evacuation percentage is set equal to the value sampled for the tidal area. The sensitivity of the resulting FN curve for the level of this threshold was found to be low.

\subsection{Hydrodynamic model simulation}

For each sampled event, the load (Rhine and Meuse discharges, sea water level, functioning of the storm surge barrier) and strength parameters (critical water levels for all defence stretches) are input for a hydrodynamic model, which simulates the water levels in the system. At each simulation time step, river water levels are compared with the threshold water levels for breach initiation. If a threshold is exceeded, a breach is initiated and water will flow through the breach out of the river. Water is thus abstracted from the river, which leads to a reduction of downstream water levels.

A defence breach is simulated by the opening of a structure which represents the breach in the model. The height of the outlet is equal to the level of the area directly behind the defence. The width of the structure opening grows in time from zero at the time of breaching to a maximum of $200 \mathrm{~m}$ after 2 days. The growth rate is based on Verheij (2003).

In order to save computing time in the MCS, the inundation of the area behind the breach is simulated in a simple way: the area behind the breach is represented by a reservoir. Due to this choice, the flood modelling could be done with an efficient 1-D model. Of course, the Dutch protected flood plains do not exactly behave as reservoirs and the simulated water levels in the reservoirs will thus not represent the water levels in the floodplains correctly. The inflow in the reservoirs, however, was found to be realistic and consistent with previously carried out detailed 1-D/2-D flood simulations. The outflow from the river into the polders is thus rep- resented well and this is what is needed most for obtaining realistic estimates of the retention effect of breaches. The water levels in the reservoirs itself are not used. Instead, for locations where breaches occur, existing 2-D flood inundation model results are taken from a database with pre-simulated flood scenarios (see next section).

The time step used in the hydrodynamic simulations is 1 hour. A full simulation period covers 1 month. The most important boundary conditions are the discharge as a function of time at Lobith and Lith (Rhine and Meuse rivers), the sea water level as a function of time (at Maasmond and the Haringvliet) and a water-level-discharge relationship at the downstream side of the IJssel river branch, which flows into the IJssel Lake (see Fig. 2).

The hydrodynamic simulations result for each sample in the defence stretches where a breach occurred, the maximum discharges through the breaches and the maximum water levels in the river at the breach locations.

\subsection{Translation of model outcomes to societal flood fatality risk measures}

For those locations where breaches were simulated, the corresponding number of fatalities is taken from a database with pre-calculated flood scenarios and consequences. These fatality figures are all determined for breaches at design conditions and simulated with a 1-D/2-D or a 2-D model (De Bruijn and Diermanse, 2013). The flood patterns were translated to fatality figures with mortality functions (Jonkman, 2007; Maaskant et al., 2009a). The simulated inflow in the polder areas may deviate from the inflow at design conditions for which the pre-calculated flood fatality figures are available. However, the sensitivity of the number of fatalities for small variations in breach inflow is small compared to other uncertainties, such as the sensitivity to the estimate of the number of breaches, the breach locations, and the evacuation success rates.

A final step of the method is to include evacuation. The number of potential fatalities per breach location is multiplied by the fraction of inhabitants who were not evacuated. A list is then generated which gives, for each of the 2000 simulated events and for each potential breach location the number of fatalities and the total number of fatalities in the event. This result is then used to construct the FN curve.

In the case study area, the number of fatalities due to a single defence breach at design conditions varies between zero and more than 3000 . The highest fatality numbers are expected due to breaches along the Lek in the transition area and just east of Rotterdam. At those locations, breaches may result in extensive flooding, large water depths and steep water level rise rates. Furthermore, these defence sections protect densely populated areas and the evacuation possibilities are limited there due to the short forecast lead time of storm surges. In the non-tidal area, the evacuation possibilities are 


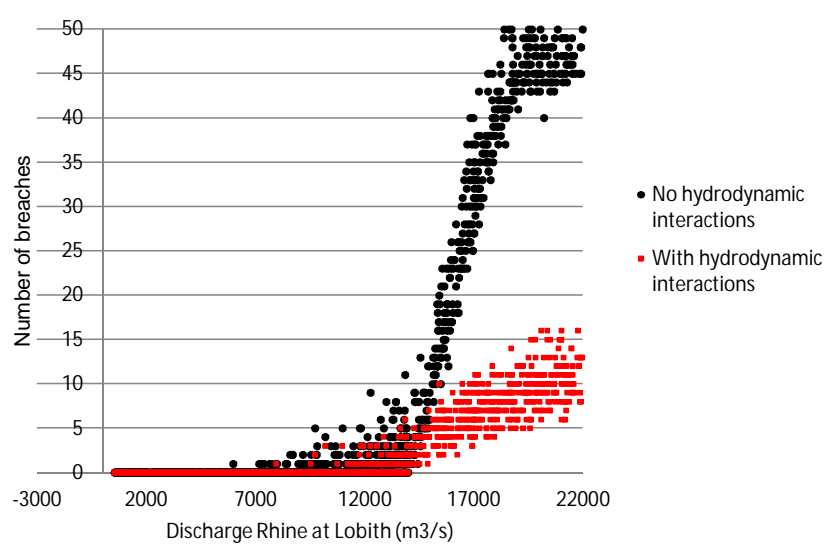

Figure 6. Effect of hydrodynamic interaction on the number of breaches in the non-tidal part of the delta.

generally better and the population density is lower. Consequently, the number of fatalities there is lower.

\section{Results for the Rhine-Meuse delta}

\subsection{Results for the current flood protection standard}

The results presented here were obtained with a set of fragility curves that were tuned to match the current protection standards (see Sect. 3.2). The selected MCS strategy resulted in an acceptable convergence of the estimate of the exceedance probabilities of $N$ fatalities for $N=10,100,500$ and 1000 and risk estimate (see Fig. 5).

Figure 6 shows the number of breaches in the non-tidal area for a simulation in which hydrodynamic interaction is taken into account and one in which this is not taken into account. In the non-tidal area, a river flood wave with a peak value of about $16000 \mathrm{~m}^{3} \mathrm{~s}^{-1}$ at Lobith (the current "design discharge" for the flood defences in that area) causes about 2-5 breaches (taking into account hydrodynamic interaction). The effect of hydrodynamic interaction is clear: it reduces the number of breaches especially due to extreme events. A breach reduces the water levels downstream and thereby the probability of additional breaches. If this alleviating effect is not considered, the number of breaches is much larger. In the upper and tidal areas, the reduction of the number of breaches due to hydrodynamic interaction is about $80 \%$. In the transition zone it is about $70 \%$. If hydrodynamic interaction is taken into account, no events with more than 20 breaches are found.

Figure 7 shows the resulting FN curve for the situation in which the defences comply with the current flood protection standard for a calculation including and excluding outflow to inundated areas, thereby indicating the effect of hydrodynamic interaction on the FN curve. The effect is large, especially for high values of $N$. The probability of events with 10,000 or more fatalities decreases from about $9 \times 10^{-5}$ to $3 \times 10^{-7}$ a year if hydrodynamic interaction is taken into account. The number of fatalities which is exceeded with a probability of 1 / 10000 a year decreases from about 10000 to 3000 .

Figure 7 also shows that the contribution of the three subareas in the delta to the flood fatality risk is not equal: the non-tidal river area contributes most to the FN curve up to 8000 fatalities. For events with more than about 8000 fatalities the tidal river area contributes most. In the tidal river area floods are rare, but potentially catastrophic. In that area many breaches may occur during a single storm surge event, especially if the storm surge barrier fails to close.

The probability of a flooding with at least one fatality is about 1 / 70 per year. The highest flood probability of a single potential breach location is 1/320 (at Heerewaarden). The PLL (potential loss of life), or annual expected number of fatalities, is about 3 . The number of fatalities corresponding to a probability of exceedance of $10^{-6}$ is 8400 for the whole area. In the non-tidal river area, the probability of high numbers of fatalities is very small. No events with more than 10000 fatalities were identified in this area. However, the probability of events with 10 to 100 fatalities is higher than in the tidal and transition area (see Table 1).

In flood risk management in the Netherlands, the $C$ value is often used as a measure for societal flood risk (Vrijling et al., 1995). This value is found by plotting a tangent of the FN curve with a slope of -2 on a logarithmic scale. The $C$ value is then equal to the value where this line crosses the line $N=1$. The slope of -2 implies a risk-averse policy: events with 1000 fatalities are considered 100 times more serious than events with 100 fatalities. An example orientation line is plotted in Fig. 8. In some other countries, a risk-neutral approach is used, reflected by a line with a slope of -1 . Although the use of the $C$ value as a tolerable risk indicator is still under discussion, and no decision on a tolerable level has been made, 1100 is frequently mentioned as a potential acceptable value for the Netherlands. This value is based on a comparison of different types of risks (man-made or natural, voluntary taken or imposed on inhabitants without their consent) and tolerance levels for those risks (Vrijling et al., 1995). Several risk indicators can be derived from the FN curve, including the probability of an event with at least one fatality, the PLL, the probability of more than $N$ fatalities and the number of fatalities associated with a certain probability (see Table 1). In the case study of the Rhine-Meuse delta, the $C$ value of the FN curve is determined by flood scenarios with more than 1000 fatalities. To reduce the $C$ value, the number of fatalities of scenarios with 1000 or more fatalities must be reduced. The scenarios which contribute most to the $C$ value are scenarios with a high Rhine discharge and unsuccessful evacuation. These scenarios often include several breaches in the central river area along the Lek River. In general, these high discharge events will be forecast days in 

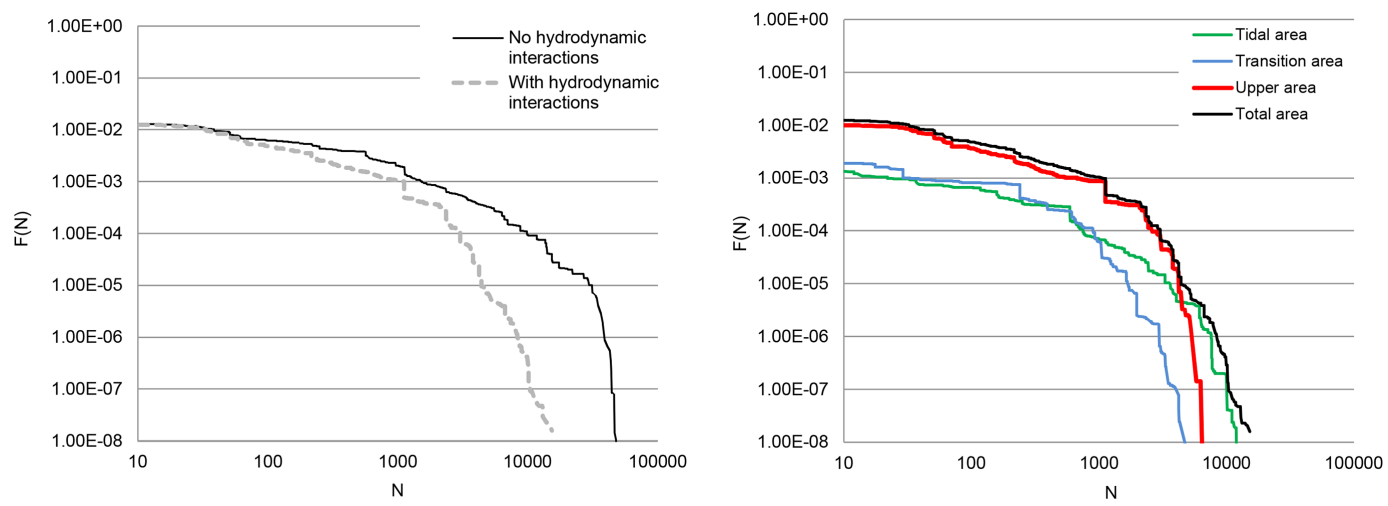

Figure 7. Resulting FN curves. Left: FN curve of the delta determined in two ways - with and without considering the effect of hydrodynamic interaction. Right: contribution of the three zones to the total FN curve (with hydrodynamic interaction).

Table 1. Indicator values derived from the FN curve for the three subareas and the total area.

\begin{tabular}{lccccc}
\hline Indicators & Tidal & Upper river & Transition & Total area & $\begin{array}{c}\text { Total } \\
\text { (no hydrodynamic } \\
\text { interaction) }\end{array}$ \\
\hline$P(N>=1)$ & $1.36 \times 10^{-3}$ & $1.01 \times 10^{-2}$ & $3.03 \times 10^{-3}$ & $1.36 \times 10^{-2}$ & $1.4 \times 10^{-2}$ \\
$P(N>=100)$ & $6.65 \times 10^{-4}$ & $3.67 \times 10^{-3}$ & $8.33 \times 10^{-4}$ & $4.87 \times 10^{-3}$ & $6.22 \times 10^{-3}$ \\
$P(N>=1000)$ & $7.1 \times 10^{-5}$ & $8.71 \times 10^{-4}$ & $6.27 \times 10^{-5}$ & $1.05 \times 10^{-3}$ & $2.06 \times 10^{-3}$ \\
$P(N>10000)$ & $4.1 \times 10^{-8}$ & - & - & $2.89 \times 10^{-7}$ & $9.39 \times 10^{-5}$ \\
$N\left(P=<10^{-6}\right)$ & 7600 & 5800 & 3000 & 8400 & 39000 \\
$C($ slope -2$)$ & 160 & 360 & 91 & 1574 & 14003 \\
$C$ (slope -1$)$ & 1.0 & 0.2 & 0.2 & 1.1 & 2.2 \\
PLL & 0.4 & 2.5 & 0.4 & 3.3 & 8.4 \\
\hline
\end{tabular}

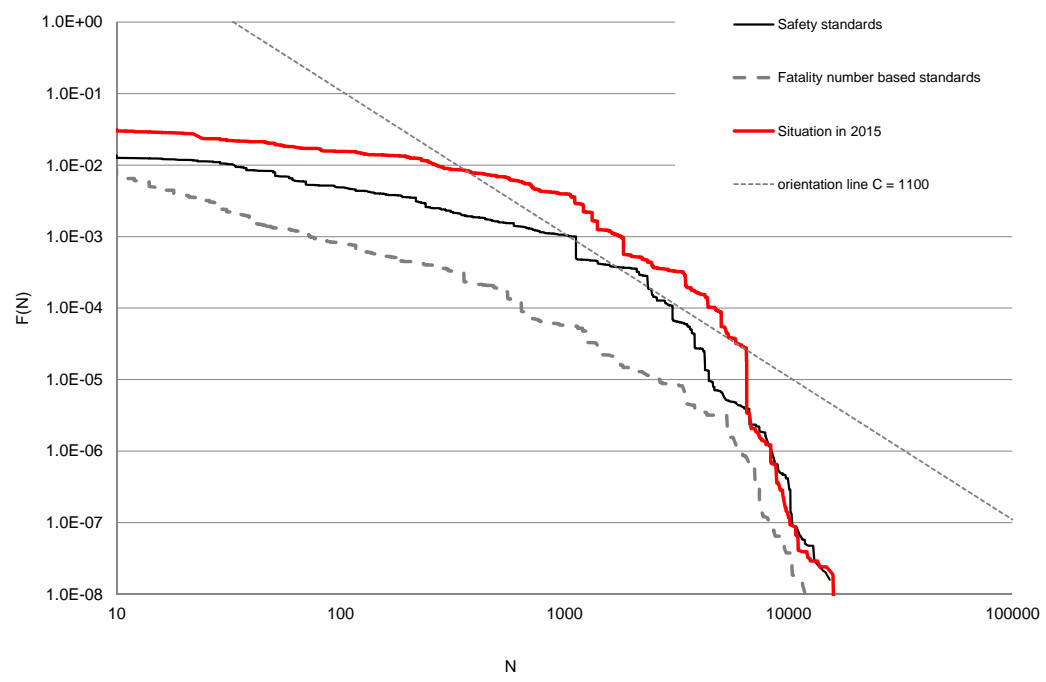

Figure 8. Resulting FN curves for the three alternative flood protection standard sets and an orientation line. 
advance. However, it may happen that levees fail before the evacuation is completed.

\subsection{Results for alternative flood risk management strategies}

The method may be used to study the effect of alternative flood risk management strategies on societal risk. To illustrate this, three alternative strategies were analysed:

1. a situation in which all flood defences comply with the current safety standards (see previous section);

2. the actual situation which is expected in 2015 after the implementation of planned projects for defence strengthening; according to new insights in dike failure mechanisms, the flood probabilities are much larger than the current flood protection standards would suggest;

3. a potential alternative set of standards, which is linked to the expected number of fatalities of the defence strengths.

In strategy 3 all defence stretches have obtained a safety standard based on the expected number of fatalities in the case of a breach. The possibilities of evacuation (which differ per area) have been taken into account in these numbers. Table 2 describes the relationship used to link the expected numbers of fatalities with flood protection standards.

To assess the societal risk corresponding with the alternative situations, the following steps have been carried out for both alternative 2 and 3 :

1. the mean values of the fragility curves have been adapted in order to make them comply with the flood probabilities corresponding with the alternatives;

2. new critical water levels have been sampled for each defence location; for the load parameters and evacuation responses the same values have been used as for alternative 1 (river discharges, water levels at the sea and storm surge barrier data);

3. flood simulations have been run for all 2000 sampled events;

4. the output has been translated to flood fatality figures per sampled event and to an FN curve.

Figure 8 shows the results. As expected, the societal risk corresponding with alternative 2 (actual probabilities in 2015) with the highest flood probabilities, is highest, and the one corresponding with alternative 3 (probabilities of failure of each defence section is based on the expected number of fatalities in case of a breach) is lowest. The differences are largest for events which cause about 1000 fatalities. The number of fatalities related to very rare flood events is comparable for all three flood risk management strategies.
Table 2. The relationship used between the expected number of fatalities given a breach (taking into account evacuation possibilities) and the required safety standard as used in alternative 3 .

\begin{tabular}{ll}
\hline $\begin{array}{l}\text { Expected number } \\
\text { of fatalities }\end{array}$ & $\begin{array}{l}\text { Flood protection } \\
\text { standard* }\end{array}$ \\
\hline$>1000$ & $1 / 100000$ \\
$500-1000$ & $1 / 30000$ \\
$100-500$ & $1 / 10000$ \\
$50-100$ & $1 / 3000$ \\
$10-50$ & $1 / 1000$ \\
$<10$ & $1 / 300$ \\
\hline * Annual failure probability per defence section \\
considered independently of other defence sections.
\end{tabular}

\section{Discussion}

The FN curve presented in the previous section provides insight into the level of the societal flood risk if the flood protection were to meet the current standards. It is not possible to draw conclusions on whether the societal risk is tolerable or too high, since no standards for societal flood fatality risks exist yet. It is, however, possible to determine which regions or defence sections contribute most to the FN curve. The results show that the discharge-dominated part of the river area contributes most to the societal flood risk. Only for events that cause 8000 fatalities or more is the contribution of the tidal river area higher.

The increase of flood protection levels clearly affects the FN curve. Other measures than defence strengthening, such as flood impact mitigating measures, would shift the curve to the left. Examples of such measures are improvements in flood warning, flood preparedness or evacuation efficiency. An improved evacuation success rates could be taken into account by changing the evacuation probability functions. Measures which affect the number of fatalities given a breach, e.g. improving building quality, raising buildings, or measures which would reduce the water depth in the flooded area can also be considered by adapting the number of fatalities corresponding with the breach location.

It is possible to use the FN curve to target risk-reducing measures and to select those measures which shift the curve downwards. If, for example, the probability of more than 10000 fatalities is considered too high, the measures should be targeted on functioning of the Maeslant Barrier or on the defence sections near Rotterdam, where the highest numbers of fatalities are found. On the other hand, if the probability of events with 1000 or more fatalities needs to be reduced, the central river area should get the most attention. In all cases, improving the probability of a successful evacuation could be an alternative to raising or strengthening of flood protection. The flood fatality risk estimates are currently being used for the development of flood risk management strategies (Van der Most et al., 2014). 
The developed modelling methodology has acceptable computation times $(9 \mathrm{~h}$ for a full Monte Carlo analysis of 2000 samples on an Intel core i7 64bit, 16 Gb RAM). The Monte Carlo approach has the additional advantage that probabilistic results can be exemplified by flooding scenarios.

The method can be applied to flood risk assessment in other deltas. It is especially suitable for large river deltas with a developed infrastructure of flood defences where hydrodynamic interaction is important. For those areas the method presented here has advantages over other methods.

\section{Conclusions}

The method presented in this paper combines a hydrodynamic model with a probabilistic framework. It includes a Monte Carlo simulation of external hydraulic forcing, fragility curves of the levees and of evacuation scenarios. The sampled events are simulated by a 1-D hydrodynamic model and combined with pre-simulated 2-D model results to obtain fatality figures. Finally, an FN curve is derived, which quantifies exceedance frequencies of numbers of fatalities. The combination of probabilistic and hydrodynamic modelbased risk analysis provides insight into the hydrodynamic interactions within the system. The method is not computationally demanding and thus allows for the analysis of the whole river delta and for the analysis of risks corresponding with various flood risk management strategies.

The method produces FN curves and various flood risk indicators as well as contributions of subareas or even individual defence sections to the overall flood risk. The results clearly show the relevance of taking hydrodynamic interaction into account in risk assessment. The flood risk including interactions is much lower than assessed when hydrodynamic interaction is not taken into account. Using the method helps to get a better understanding of the system and its spatial interdependencies.

The results show that the discharge-dominated part of the river area contributes most to the societal flood fatality risk. Only for events which cause 8000 fatalities or more does the tidal area contribute most.

The method makes it possible to evaluate flood protection or mitigation measures in terms of societal flood fatality risk reduction. The method has already been used to analyse strategies involving defence strengthening, improving the failure probability of the Maeslant Barrier and improving evacuation and other emergency response measures (De Bruijn et al., 2014; Klijn et al., 2013).
Acknowledgements. The research presented in this paper is part of the Dutch Delta Programme and was commissioned by the Ministry of Infrastructure and Environment, Rijkswaterstaat Agency.

Edited by: P. Bubeck

Reviewed by: S. Vorogushyn and two anonymous referees

\section{References}

Apel, H., Thieken, A. H., Merz, B., and Blöschl, G.: Flood risk assessment and associated uncertainty, Nat. Hazards Earth Syst. Sci., 4, 295-308, doi:10.5194/nhess-4-295-2004, 2004.

Apel, H., Merz, B., and Thieken, A. H.: Influence of dike breaches on flood frequency estimation, Comput. Geosci., 35, 907-923, 2009.

Allaix D. L. and Carbone V. I.: An improvement of the response surface method, Struct. Saf., 33, 165-172, 2011.

Beckers, J. V. L. and De Bruijn, K. M.: Analyse van Slachtofferrisico's. Waterveiligheid 21e eeuw. Report 1204144-005, Deltares, Delft, the Netherlands, 2011.

Beckers, J., De Bruijn, K.M., and Riedstra, R.: Life safety criteria for flood protection standards, in: Floods: From Risk to Opportunity, IAHS Publ. 357, 21-25, 2012.

Dawson R. and Hal, J.: Adaptive importance sampling for risk analysis of complex infrastructure systems, Proc. R. Soc. A, 462, 3343-3362, 2006.

De Bruijn, K. M. and Diermanse, F. L. M.: A new method to assess societal flood risk. Developed for the riverrine area in the Netherlands, Deltares, Delft, the Netherlands, 2013.

De Bruijn K. M. and Klijn F.: Risky places in the Netherlands: a first approximation for floods, J. Flood Risk Manage., 2, 58-67, 2009.

De Bruijn, K. M., Mens, M. J. P., and Klijn, F.: A method for developing long-term strategies for flood risk manage-ment, in: Flood risk management: Research and Practice, edited by: Samuels, P., Huntington, S., Allsop, W., and Harrop, J., Taylor \& Francis group, London, UK, 142 pp., 2008.

De Bruijn K. M., Beckers J. and Van der Most H.: Casualty risks in the discussion on new flood protection standards in The Netherlands, in: Flood Recovery, Innovation and Response II, edited by: De Wrachien, D., Proverbs, D., Brebbia, C. A., Mambretti, S., WIT Press, 73-83, 2010.

De Bruijn, K. M., Klerk, W. J. and Diermanse, F.: Analyse groepsrisico's in Nederland t.b.v. de normeringsdiscussie, Report 1209190, Deltares, Delft, 2014 (in Dutch).

Den Heijer, F and Diermanse, F. L. M.: Towards risk-based assessment of flood defences in the Netherlands: an operational framework, In: Comprehensive Flood Risk Management: Research for Policy and Practice, proceedings of the FloodRisk 2012 conference in Rotterdam, November 2012, CRC Press, ISBN 9780415621441, 2012.

Dhondia, J. F. and Stelling, G. S.: Sobek one dimensional-two dimensional integrated hydraulic model for flood simulation - its capabilities and features explained, 6th International Conference on Hydroinformatics, Singapore, 21-26 June 2004.

Di Mauro, M. and De Bruijn, K. M.: Quantitative methods for estimating flood fatalities: towards the introduction of loss of life estimation in the assessment of flood risk, Nat. Hazards, 63, 10831113, doi:10.1007/s11069-012-0207-4, 2012. 
Diermanse, F. L. M., De Bruijn, K. M. and Beckers, J.: Importance sampling for efficient modelling of hydraulic loads in flood risk analysis, Stoch. Env. Res. Risk A., doi:10.1007/s00477-0140921-4, online first, 2014.

Gouldby, B. P., Lhomme, J., McGahey, C., Panzeri, M., Hassan, M., Kakeh Burgada, N., Magaña Orue, C., Alvarez Diaz, C., Jamieson, S. R., Wright, G., Van Damme, M., and Morris, M.: A flood system risk analysis model with dynamic sub-element 2-D inundation model, dynamic breach growth and life-loss, in: Comprehensive Flood risk management, edited by: Klijn, F. and Scweckendiek, T., Taylor \& Francis Group, London, ISBN 9780-415-62144-1, 655-662, 2013.

Hall, J. W., Sayers, P. B., and Dawson, R. J.: National-scale assessment of current and future flood risk in England and Wales, Nat. Hazards, 36, 147-164, 2005.

Hesselink, A. W., Stelling, G. S., Kwadijk, J. C. J., and Middelkoop, H.: Inundation of a Dutch river polder, sensitivity analysis of a physically based inundation model using historic data, Water Resour. Res., 39, 1234 pp., doi:10.1029/2002WR001334, 2003.

IMDC: Sigmaplan Maatschappelijke Kosten Baten Analyse, Deelopdracht 1, Faserapport 2: Nulalternatief: water-standen, overstromingskaarten, schade, slachtoffers en risico. IMDC rapport I/RA/14082/04.017, 2005.

Jongejan, R. B., Maaskant, B., Horst, W., Havinga, F. J., Roode, N., and Stefess, H.: The VNK2 project: a detailed, large-scale quantitative flood risk analysis for the Netherlands. Proceedings of the 5th International Conference on Flood Management (ICFM5), Tokyo-Japan, 27-29 September 2011.

Jonkman, S. N.: Fatality estimation in flood risk assessment, Theory and applications, PhD thesis TU Delft, Delft, the Netherlands, 2007.

Jonkman, B., Maaskant, B., and Jongejan, R.: Landsdekkende schattingen van slachtofferrisico's voor overstromingen. Vervolgstudie verkenning slachtofferrisico's in het hoogwaterbeschermingsbeleid, Projectnummer: 9T2050.B0, 2008 (in Dutch).

Klijn, F, De Bruijn, K. M., Knoop, J., and Kwadijk, J.: Assessment of the Netherlands' Flood Risk Management Policy Under Global Change, Ambio, 41, 180-192, doi:10.1007/s13280-0110193-x, 2012.

Klijn, F., Kolen, B., Knoop, J., Wagenaar, D., De Bruijn, K., and Bouwer, L.: Maatschappelijke ontwrichting door overstromingen voorkomen? Deltares Report 1208052, Delft, The Netherlands, 2013 (in Dutch).

Kok M., Huizinga H. J., Vrouwenvelder A. C., and Van den Braak W. E. M.: Standaardmethode 2005. Schade en slachtoffers als gevolg van overstromingen. Rapport 999.10, HKV Lijn in Water, Lelystad, the Netherlands, 2005 (in Dutch).

Kok, M. and Van der Doef, M.: Leidraad overstromingsberekeningen voor VNK2, 2008 (in Dutch).

Lalande, J. P.: The Influence of Xynthia on Policy and Practice, FloodRisk 2012: From science to practice, Rotterdam, November 2012, available at: www.floodrisk2012.net/documents/ presentations/121121InfluenceXynthiapolicyandpractice.pdf, 2012.

Marchand, M., Buurman, J., Pribaid, A., and Kurniawan, A.: Damage and casualties modelling as part of a vulnerability assessment for tsunami hazards: a case study from Aceh, Indonesia, J. Flood Risk Manage., 2, 120-131,doi:10.1111/j.1753318X.2009.01027.x, 2009.
Maaskant, B., Jonkman, S. N., and Kok, M.: Analyse slachtofferaantallen VNK-2 en voorstellen voor aanpassingen van slachtofferfuncties. HKV Lijn in Water Rapport PR1669.10, Delft, the Netherlands, 2009a (in Dutch).

Maaskant, B., Kolen, B., Jongejan, R., Jonkman, S., and Kok, M.: Evacuatieschattingen Nederland. Rapport PR1718.10. HKV Lijn in Water, Delft. the Netherlands, 2009b (in Dutch).

Ministerie van Verkeer and Waterstaat: Hydraulische Randvoorwaarden primaire waterkeringen voor de derde toetsronde 20062011, Den Haag, the Netherlands, 2007 (in Dutch).

Ministerie van Verkeer and Waterstaat: Het Nationaal Waterplan, Beleidsnota, 279 pp., 2009 (in Dutch).

Olson, K. R. and Morton, L. W.: The effects of 2011 Ohio and Mississippi river valley flooding on Cairo, Illinois, area, J. Soil Water Conserv., 67, 42A-46A, 2012.

Penning-Rowsell, E., Floyd, P., Ramsbottom, D., and Surendran, S.: Estimating injury and loss of life in floods: a deterministic framework, Nat. Hazards, 36, 43-64, 2005.

Sayers, P. B., Hall, J. W., Rosu, C., Chatterton, J. B., and Deakin, R.: Risk assessment of flood and coastal defences for strategic planning (RASP) - A high level methodology, in: DEFRA Conference of Coastal and River Engineers, Keel University, UK, 2002.

Steenackers G., Presezniak, F., and Guillaume P.: Development of an adaptive response surface method for optimization of computation-intensive models, Comput. Ind. Eng., 57, 847-855, 2009.

Steenbergen, H. M. G. M., Lassing, B. L., Vrouwenvelder, A. C. W. M., Waarts, and P. H. : Reliability analysis of flood defence systems., HERON, 49, 51-73, 2004.

US Department of the Interior: Dam safety public protection guidelines. A risk framework to support dam safety decision-making, Denver, Colorado, 2011.

Van der Meij. R.: Overhoogte in Rijnmond-Drechtsteden, Bepaling gebieden waar overhoogte als oversterkte mag worden beschouwd, Deltares in opdracht van Rijkswaterstaat, 2013 (in Dutch).

Van der Meij, R. and Lopez de la Cruz, J.: Automated determination of flood risk through fragility, EGU General Assembly, Vienna, Austria, 7-12 April 2013, EGU2013-3219, 2013.

Van der Most, H., Tánczos, I., De Bruijn, K. M., Wagenaar, D.: New Riskbased standards for flood protection in the Netherlands, in: Proceedings of the ICFM6 conference 16-18 September, Sao Paulo, Brasil, 2014.

Van Mierlo, M. C. L. M., Vrouwenvelder, A. C. W. M., Calle, E. OF., Vrijling. J. K., Jonkman, S. N., De Bruijn, K. M., and Weerts, A. H.: Assessment of floods risk accounting for River System Behaviour, Int. J. River Basin Manage., 5, 93-104, 2007.

Verheij, H.: Aanpassen van het bresgroeimodel in HIS-OM: bureaustudie, Reprot Q3299, WL, Delft Hydraulics, Delft, the Netherlands, 2003.

Vorogushyn, S., Merz, B., Lindenschmidt, K.-E., and Apel, H.: A new methodology for flood hazard assessment considering dike breaches, Water Resour. Res., 46, W08541, doi:10.1029/2009WR008475, 2010.

Vorogushyn, S., Merz, B., and Apel, H.: Analysis of a detention basin impact on dike failure probabilities an flood risk for a channel-dike-floodplain system along the river Elbe, Germany, J. Hydrol., 436-437, 120-131, 2012. 
Vrijling, J. K, van Hengel, W., and Houben, R. J.: A framework for risk evaluation, J. Hazard. Mater. 43, 245-261, 1995.
Vrouwenvelder A. C. W. M., Van Mierlo, M. C. L. M., Calle, E. O. F., Markus, A. A., Schweckendiek, T., and Courage, W. M. G.: Risk analyis for flood protection systems. Main report, TNO and Deltares, Delft, the Netherlands, 2010. 